\title{
Interférences
}

Ars scribendi

$9 \mid 2016$

Varia

\section{Les terribles aigreurs du Péléide}

Quelques réflexions sur l'ode 1,6 d'Horace

\section{Maryse Schilling}

\section{CpenEdition}

Journals

Édition électronique

URL : http://journals.openedition.org/interferences/5652

DOI : 10.4000/interferences.5652

ISSN : $1777-5485$

Éditeur

HiSoMA - Histoire et sources des Mondes antiques

Référence électronique

Maryse Schilling, "Les terribles aigreurs du Péléide », Interférences [En ligne], 9 | 2016, mis en ligne le 18 janvier 2018, consulté le 15 septembre 2020. URL : http://journals.openedition.org/interferences/ 5652 ; DOI : https://doi.org/10.4000/interferences.5652

Ce document a été généré automatiquement le 15 septembre 2020

Tous droits réservés 


\title{
Les terribles aigreurs du Péléide
}

\author{
Quelques réflexions sur l'ode 1,6 d'Horace*
}

Maryse Schilling

1 Les exploits d'Agrippa, la terrible colère d'Achille ou les errances d'Ulysse : voilà des sujets que le poète Horace préfère laisser à d'autres : «Non, nous ne tentons pas, faible que nous sommes, ces sujets sublimes ${ }^{1} »($ Carm. 1, 6, 9). Par cette spectaculaire mise en scène de ses choix génériques, Horace affiche clairement dans l'ode 1, 6 son rejet du genre épique et sa préférence pour la lyrique. Le refus n'excluant néanmoins pas une forme de courtoisie ${ }^{2}$, Horace flatte au passage deux personnages contemporains, le poète L.Varius Rufus et $\mathrm{M}$. Vipsanius Agrippa. La recusatio repose en effet sur l'affirmation que les exploits du général mériteraient d'être traités dans un genre noble, une épopée, que seul Varius sera en mesure de composer, comme Homère chanta autrefois la colère d'Achille ou les errances d'Ulysse (v. 1-9). Dans la suite de l'ode, Horace feint de déplorer ses faiblesses en matière d'épopée : il développe ainsi une comparatio paratactica ${ }^{3}$ et ajoute au topos de l'alter Homerus d'autres éléments caractéristiques du procédé de la recusatio. L'opposition paradigmatique tenuitas/ granditas lui permet de mettre en évidence le déséquilibre existant entre ses propres forces et celles que réclament les genres nobles ${ }^{4}$ : face aux sujets épiques ou tragiques qui sont grandes, Horace s'avoue tenuis (v. 9). Il allègue aussi sa modestie (pudor, v. 9), l'interdiction qu'il a reçue de sa muse imbellis ${ }^{5}$ (v.10), et enfin un défaut de compétence (culpa ingeni, v. 11), qui le poussent à s'en tenir à des sujets légers, à savoir les combats des jeunes filles plutôt que ceux de César (v. 17-20).

Évidemment, le lecteur familier du procédé de la recusatio, dans laquelle se sont illustrés Catulle et Virgile avant Horace ${ }^{6}$, n'aura pas de mal à reconnaître, derrière le masque de l'humilis poeta, l'auteur des Satires qui manie ici l'ironie avec un plaisir à peine dissimulé. N'est-il pas étrange en effet de parler du stomachus Pelidae pour

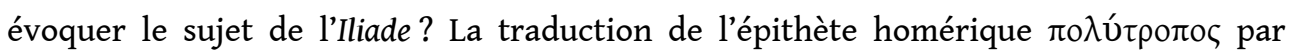
l'adjectif latin duplex est-elle satisfaisante ? Si le caractère inapproprié, voire trivial, des expressions utilisées par Horace pour évoquer des sujets héroïques a été depuis longtemps relevé par les différents commentateurs des Odes ${ }^{7}$, peu d'entre eux se sont attachés à en expliquer précisément la portée. Ce n'est qu'en 1991 que paraît une 
analyse minutieuse de cet «élégant jeu d'esprit ${ }^{8} »:$ C. F. Jr. Ahern publie dans Classical Philology un article intitulé "Horace's Rewriting of Homer in "Carmen" 1.6 ", où il étudie dans le détail les distorsions que le poète latin fait subir au langage homérique. Selon lui, la portée de ce jeu est double : il s'agit pour Horace d'exprimer un rejet de l'épopée et une préférence pour l'esthétique alexandrine - au moyen de corrections at play et de jeux philologiques qui prennent le langage homérique pour cible - et de parodier les auteurs homérisants de son époque'. C. F. Ahern justifie ainsi l'utilisation du terme "parodie " souvent appliqué à l'ode 1,6 par les commentateurs, sans pour autant que le sens ou la portée de cette notion soient expliqués ou analysés de manière satisfaisante. Dans le présent article, je suivrai en grande partie la démarche et le point de vue adoptés par C. F. Ahern, qui consistent à mettre en relief la dimension ludique de l'ode 1,6 . Je propose néanmoins de montrer que la cible du jeu horatien n'est pas le langage spécifiquement homérique, mais plus largement l'épopée. En outre, le langage épique ne me semble pas uniquement parodié ou moqué, mais profondément exploré et interrogé par le poète. En effet, bien que les distorsions mises en évidence par C. F. Ahern produisent d'abord un effet humoristique, elles dépassent à mon sens le jeu philologique ou la parodie. Elles manifestent la capacité d'Horace à défier les genres nobles et illustrent sa pleine maitrise du langage épique, qu'il expérimente, réinvestit et interroge. Les distorsions constituent par ailleurs, nous le verrons, un faisceau d'indices programmatiques qui, en créant une mise en tension générique, permet à Horace de faire surgir un questionnement qui a pour objet non seulement les genres à l'époque d'Auguste, les valeurs véhiculées par l'épopée, mais aussi sa propre poétique.

\section{Les res gestae d'Agrippa : une nouvelle Iliade?}

Dans les incipits de ses odes, Horace aime utiliser des motti ${ }^{10}$, traductions de vers de Pindare ou d'Alcée, pour donner un cadre particulier à son poème et offrir à son lecteur le plaisir de reconnaître des emprunts grecs. Dans l'ode 1, 6 en revanche, le poète met immédiatement le lecteur face à un contexte pleinement romain avec la convocation de deux personnages de la scène littéraire et politique du principat, L. Varius Rufus et M. Vipsanius Agrippa (v. 1-4) :

Scriberis Vario fortis et hostium

uictor, Meonii carminis alite,

quam rem cumque ferox nauibus aut equis

miles te duce gesserit.

«Tu seras célébré par Varius qui écrira ton courage et ta victoire sur tes ennemis, lui l'oiseau de la poésie méonienne, et tout ce que, portés sur des navires ou des chevaux, tes farouches soldats ont accompli sous ton commandement ${ }^{11}$. "

La convocation du poète Varius, célèbre à la cour d'Auguste, et de la figure d'Agrippa nous interdit, dès les premiers vers, de penser que la recusatio n'est qu'un jeu littéraire ou un art poétique se tenant à l'écart de préoccupations contemporaines ${ }^{12}$. Faire d'un poète contemporain un alter Homerus (Meonii carminis alite, v. 2) ne constitue pas seulement un topos de la recusatio, permettant à l'humilis poeta de répartir les tâches (moi je fais de la lyrique, Varius de l'épopée) et de se défausser sur un tiers. Il s'agit de réfléchir sur ce que pourrait être une épopée composée à l'époque du prince. Varius en serait l'auteur tout désigné, tandis que la figure d'Agrippa constituerait une sorte d'Achille ou d'Ulysse des temps modernes. L'emploi du futur passif scriberis, premier mot de l'ode, place l'accomplissement de cette entreprise dans un futur proche et rend 
l'énoncé assertif. On peut d'ailleurs voir dans ce verbe initial un détournement des futurs performatifs ${ }^{13}$ ( $\mu v \eta ́ \sigma o \mu \alpha l$ par ex.) que l'on trouve fréquemment dans la poésie mélique et qui indiquent dès le premier vers l'intention qu'a l'aède de commencer le chant $^{14}$. Ici, Horace détourne la convention de plusieurs manières. En remplaçant le verbe de parole par le verbe scribere, on passe d'une poésie orale à une poésie scripturale - j'y reviendrai. D'autre part, à la $1^{\text {re }}$ personne du singulier renvoyant à l'aède se substitue un passif de $2^{\mathrm{e}}$ personne, qui a pour effet de mettre en relief l'objet du carmen, Agrippa, mais aussi de souligner que le chant est délégué à un tiers (Vario).

Dans le même ordre d'idées, la première strophe de l'ode constitue une double prétérition : Horace, qui feint de céder immédiatement la parole à Varius et rejettera plus nettement encore la tentation de composer une épopée en l'honneur d'Agrippa dans la strophe 2, en ébauche ipso facto le récit en miniature (v. 1-4). C'est un procédé que l'on trouvera à nouveau employé dans l'ode 2,1. Horace y évoque les récits des guerres civiles composés par Pollion et offre ainsi une relecture des Histoires du célèbre poète, dont les scènes de bataille confinent parfois à l'hypotypose : Horace évoque le son des cors et nous laisse entrevoir le scintillement des casques et la boue qui décore les généraux. D. Voisin a étudié de manière très précise le résumé qu'Horace donne des récits de Pollion et note en particulier l'utilisation d'un vocabulaire et de tournures épiques ou archaïques qui permettent de mettre l'accent sur la dimension tragique des événements racontés : le terme archaïque ciuicum (v. 1), ou encore le pluriel «poétique et grandiose" cruoribus au lieu de sanguinis (v. 5) ${ }^{15}$. Dans la synopsis de l'épopée d'Agrippa que composera Varius, Horace procède de la même manière. Dans ces vers 1 à 4 , il imite en effet les tournures et les procédés épiques, mais pour composer cette fois un panégyrique guerrier en miniature et esquisser, en quelques traits bien marqués, un portrait d'Agrippa en figure héroïque.

Notons pour commencer que l'identification du sujet de scriberis, premier mot de l'ode, est retardée par l'emploi d'une cataphore rhétorique destinée à mettre en valeur le nom d'Agrippa: ce dernier n'apparaît qu'au vers 5, mais les vers précédents, qui relatent ses exploits, dissimulent des indices trahissant par avance le nom du héros. F. Cairns ${ }^{16}$ fait en effet remarquer qu'au vers 3 se cache un jeu de mots : les termes ferox

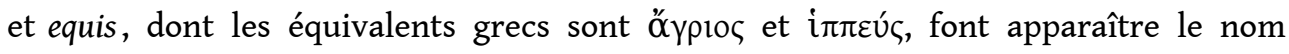
Agrippa. Horace propose ainsi une étymologie élogieuse, valorisante ${ }^{17}$, qui suggère que le général romain a tout d'un héros homérique : un nom grec et une appellation d'heureux augure. C'est là surtout le premier jeu érudit qu'Horace offre à son lecteur lettré : outre le plaisir intellectuel qu'elle procure au lecteur et la mise en valeur du héros qu'elle permet, l'énigme démontre déjà l'habileté du poète. La construction de la figure historique en héros épique s'organise également autour de procédés métriques : les adjectifs fortis et uictor (v. 1 et 2), désignant la force du général, encadrent et enserrent le terme hostium, comme si la disposition des mots dans l'espace poétique mimait l'action épique. Le rejet de uictor au vers suivant fait de la victoire du général un résultat presque immédiat de sa force sur ses ennemis. Le groupe nauibus aut equis, au vers 3 , constitue quant à lui, notent R. G. M. Nisbet et M. Hubbard ${ }^{18}$, une variation par rapport à l'expression terra marique et à la formule épique equis uirisque; la variation permet de mettre en relief le terme nauibus et de rappeler ainsi les qualités d'un général qui s'illustra brillamment sur mer ${ }^{19}$ : le lecteur pensera évidemment à Nauloque ou à Actium. Clôturant la description en miniature, l'ablatif absolu te duce (v. 4) fait quant à lui écho à l'expression te duce Caesar qui apparaît au vers 52 de l'ode 1, 2, et sans 
doute à l'expression en chiasme de l'ode suivante, Teucro duce et auspice Teucro $(1,7,27)$ : la figure épique du chef trouve ainsi un prolongement favorable dans des échos ménagés avec un héros contemporain, le prince, et une figure du cycle troyen, Teucer. Mais la plus grande preuve de l'habileté d'Horace réside probablement dans sa capacité à insérer ces procédés mettant en valeur la geste d'Agrippa dans une strophe asclépiade qui, nous rappelle J.Dangel, constitue pour le poète "un mètre anti-méonien » n'atteignant pas « aux degrés du grand style héxamétrique ${ }^{20}$ »- bien qu'il ne soit pas toutefois exempt de solennité.

7 Dans cette mini épopée célébrant les victoires et la force d'Agrippa, un élément ambigu est à prendre en considération: le terme ferox (v.3). Cet adjectif, caractérisant le comportement des soldats du général (singulier collectif miles), peut en effet être entendu en latin en bonne ou mauvaise part. S'il peut désigner la fierté et la pugnacité des soldats face à leurs ennemis, l'adjectif ferox, morphologiquement dérivé de ferus ${ }^{21}$, qui caractérise les bêtes sauvages (ferae), renvoie originellement à la sauvagerie, à la bestialité, à la cruauté animale. Les choix souvent très différents des traducteurs de l'ode rendent d'ailleurs compte de sa polyvalence. Si, pour la CUF, F. Villeneuve traduit par l'adjectif positif « fier $»^{22}$, N. Rudd choisit dans sa traduction anglaise pour Loeb le terme ambivalent " fierce $»^{23}$. Une analyse des occurrences du terme dans le recueil des Odes ne nous permet pas de conclure à un emploi horatien strictement positif ou péjoratif. En effet, sont feroces des entités ou figures aussi bien positives (le poète Alcée, le Latium, ou Rome elle-même, mais aussi le héros Hector $^{24}$ ) que négatives : l'adjectif est utilisé dans les Odes pour évoquer les barbares qui habitent les confins du monde et sont ennemis de Rome (Parthes ou Sygambres ${ }^{25}$ ), pour caractériser ironiquement le lâche Pâris ${ }^{26}$, ou encore pour désigner de manière ambiguë l'attitude de Cléopâtre, fière et constante dans la mort ${ }^{27}$. Aussi, par sa polyvalence ${ }^{28}$, le terme jette-t-il discrètement une ombre sur cette épopée d'Agrippa. Si le sens à donner à ferox est difficile à cerner, il est à peu près certain que le poète, qui condamne, dans les Épodes et les Odes, les guerres civiles comme un scelus ${ }^{29}$ qu'il faut expier, ne peut considérer ici les exploits guerriers d'Agrippa comme proprement positifs. Certes, il y eut Actium et Nauloque, mais il y eut aussi Philippes à laquelle Horace participa dans le camp adverse, celui de Brutus $^{30}$, et Pérouse, qui ne fut pas une victoire des plus glorieuses. Par ailleurs, si l'on revient une fois encore à la recusatio de l'ode 2,1 , la manière dont Horace y parle des guerres civiles ne laisse pas de doute sur l'interprétation que l'on peut donner du terme ferox. En effet, lorsqu'il évoque les récits de Pollion, Horace souligne surtout le caractère tragique et bien peu héroïque des combats des guerres civiles. Il use d'images si frappantes que D. Voisin parle, pour les strophes 5 à 7 , d'une lecture "épicotragique $^{31}$ » des Histoires de Pollion, en particulier des épisodes de Pharsale et de Thapsus : les chefs sont souillés par la boue qui les décore (magnos... duces / non indecoro puluere sordidos, v. 21-22), les chevaux et leur cavalier sont épouvantés (terret, v. 20), les plaines d'Italie sont engraissées par le sang latin qui ne sèche pas (Latino sanguine pinguior / campus, v. 28-2932), enfin les combats sont impies (impia proelia, v. 30). La matière qui constitue ces Histoires est elle-même périlleuse pour leur auteur : pour Horace, l'historien, comme l'homme d'action, se met en danger, et Pollion marche per ignes suppositos cineri doloso (Carm. 2, 1, 7-8).

8 L'ode 2,1 et l'ode 1, 6 montrent que la recusatio chez Horace n'est pas une manière de répartir les tâches ou de rejeter purement et simplement l'épopée. En imaginant ce que pourrait être une épopée contemporaine, dont il nous offre une synopsis très travaillée $(1,6)$, ou en proposant une relecture personnelle de passages potentiellement épiques 
$(2,1)$, le poète s'aventure sur le terrain du genre noble qu'il explore et sur lequel il manifeste sa pleine maîtrise des procédés conventionnels. S'il s'avoue humilis, dans la suite de la recusatio, il manifeste bien, dès les premiers vers, sa grande habileté et sa maîtrise du langage et des codes épiques. Par ailleurs, l'usage de l'ambiguïté du terme ferox montre qu'en remettant en question l'épopée Horace n'est pas seulement préoccupé par la question des genres littéraires : ce sont aussi les valeurs guerrières qu'il remet en cause, et surtout les guerres civiles. Dès lors, la question sous-jacente, et qui est aussi bien littéraire que morale, est la suivante : peut-on vraiment raconter les combats menés par Agrippa pendant les guerres civiles sur un mode épique, comme autrefois Homère chantait la guerre de Troie dans l'lliade?

\section{Le détournement du langage épique}

9 À cette question, Horace donne, du moins pour ce qui le concerne, une réponse très claire dans l'ode 1, 6. En effet, le changement brusque dans l'énonciation à la seconde strophe, le nos au début du vers 5, qui s'oppose au tu contenu dans scriberis, ainsi que le balancement de la négation, neque... nec..., marquent une rupture nette avec le discours adressé à Agrippa : finalement, c'est pour mieux lui dire qu'il ne fera pas son éloge qu'Horace a convoqué ce dernier (v. 5-9) :

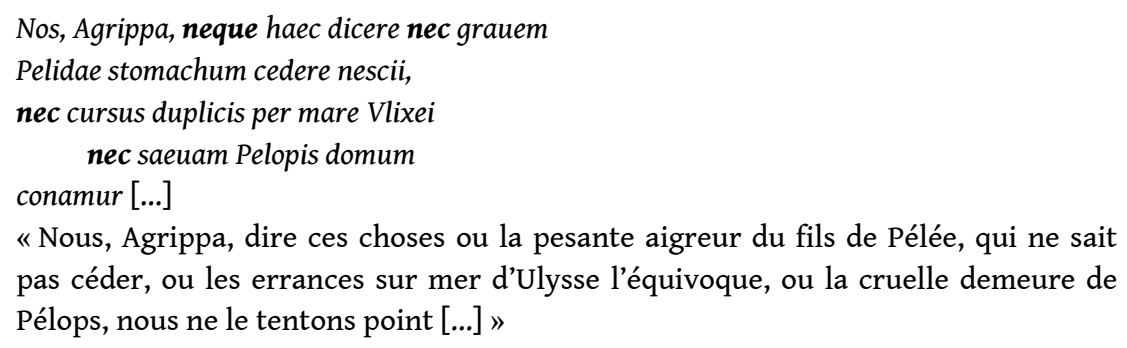

10 La $1^{\text {re }}$ personne (nos) fait soudain irruption dans l'ode, changeant ainsi la situation d'énonciation qui mettait en valeur une relation bilatérale (Varius/Agrippa, l'auteur de l'épopée / son héros). Horace intervient pour énumérer les sujets qu'il se refuse à chanter: les exploits d'Agrippa (haec), le sujet de l'Iliade (grauem stomachum Pelidae, v. 6), celui de l'Odyssée (cursus duplicis Vlixei, v. 7) et la tragédie de Thyeste (saeuam Pelopis domum, v. 8). La reprise anaphorique de nec/neque devant chacun des quatre sujets héroïques évoqués permet au poète de les mettre sur le même plan et, évidemment, de marteler son refus d'être lui aussi un alter Homerus ${ }^{33}$. La potentielle épopée de Varius se trouve ainsi élevée au rang des grandes épopées ou tragédies, et la geste d'Agrippa est mise sur le même plan que l'histoire d'Achille ou d'Ulysse. D'ailleurs, la mention de la maison de Pélops au vers 8 est sans aucun doute une allusion de la tragédie de Thyeste, écrite par Varius et jouée lors du triple triomphe d'Auguste en 29 av. J.-C. ${ }^{34}$. Horace mêle donc aux mentions des épopées homériques une œuvre contemporaine du principat $^{35}$ et semble ainsi flatter le poète. Le lecteur ne se méprendra évidemment pas sur la sincérité de cette modestie, habitué depuis Catulle et les poetae noui à reconnaître et à goûter un procédé qui constitue davantage un jeu avec les modèles et les codes génériques qu'un véritable aveu de faiblesse. Il lui appartient dès lors d'identifier les indices qui trahissent la véritable posture du poète dans l'ode face au genre épique. 


\section{L'anti-appel à la muse}

11 Si l'on regarde de plus près les expressions qui résument les sujets héroïques que refuse de chanter Horace, on remarque que les épitomés de l'Iliade, de l'odyssée et de la tragédie de Thyeste apparaissant aux vers 5,6 et 7 obéissent à une même structure syntaxique : un nom commun, noyau central de l'expression (stomachus, cursus, domus), un nom propre complément du nom (Pelidae, Ulixei, Pelopis) et un adjectif (grauis, duplicis, saeuus) - avec une expansion supplémentaire pour qualifier le Péléide, le syntagme cedere nescii. Le caractère trivial (stomachus), maladroit (duplex) ou clairement négatif (saeuus, cedere nescii) des termes choisis ne manquera pas de surprendre le lecteur de l'ode. Après avoir subtilement montré sa capacité à faire lui aussi de l'épopée, Horace, dans la deuxième strophe, accumule les décalages et les maladresses, dont il convient à présent d'éclairer la portée.

Intéressons-nous pour commencer à l'expression grauis stomachus Pelidae, qui résume le sujet de l'Iliade aux vers 5 et 6 . Plusieurs commentaires ${ }^{36}$ relèvent à juste titre que l'expression est incongrue, provoque un effet de surprise. Dans son article « Horace's Rewriting of Homer in "Carmen" 1.6", C. F. Ahern fait en particulier remarquer que l'expression grauis stomachus est une traduction volontairement parodique de la $\mu \tilde{\eta} v 1 \varsigma$

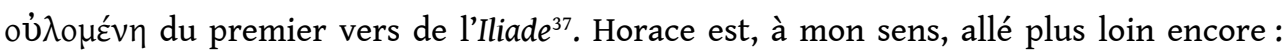
c'est en réalité l'intégralité de la célèbre adresse à la muse ouvrant l'Iliade qu'il détourne ici :

Homère, Il. 1, 1-2 :

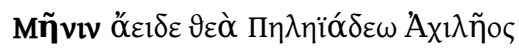

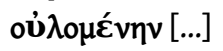

Horace, Carm. 1, 6, 5-6 :

Nos, Agrippa, neque haec dicere nec grauem

Pelidae stomachum [...]

Le poète de Venouse se présente d'abord lui aussi comme un aède. Notons en effet que l'on passe soudain d'une poésie écrite à une poésie récitée ou chantée : le premier mot du poème, scriberis, mettait en valeur le caractère scriptural de la poésie de Varius tandis que, pour évoquer sa propre poésie, Horace utilise désormais le verbe dicere ${ }^{38}$. Néanmoins, la performance orale est évoquée ici pour être mieux rejetée : à l'injonction performative de l'aède, ớ $\varepsilon 1 \delta \varepsilon$, Horace oppose un refus doublement marqué, dicere étant encadré dans le vers par une double négation (neque/nec).

Ensuite, c'est la convention épique voulant que le poète délègue sa parole à la muse qu'Horace détourne. Le nos qui ouvre brutalement le vers 5 signale la ferme volonté du poète d'assumer lui-même ou non le récit épique. Quant à la muse, qui disparait ici au profit de la figure du poète, elle n'est certes pas absente, mais elle n'apparaît que plus loin, et non comme inspiratrice. Elle incarne au contraire dans l'ode une forme de censure puisqu'elle intervient pour interdire au poète de faire de l'épopée: elle se révèle en cela une puissante force de dissuasion, comme le souligne la juxtaposition de potens et de uetat au vers 10. En outre, on trouve à la place du vocatif $\theta \varepsilon \grave{\alpha}$ le vocatif Agrippa. Il est plaisant de voir la muse remplacée par le général d'Auguste, l'inspiratrice divine par le commanditaire. Notons enfin la disposition des mots dans ces vers 5 et 6 , qui constitue un jeu avec le modèle homérique : alors que la $\mu$ ñvı était mise en valeur par sa place liminaire, chez Horace au contraire le stomachus est nettement rejeté au 
vers suivant, et l'ordre de la disjonction homérique entre le substantif et son adjectif

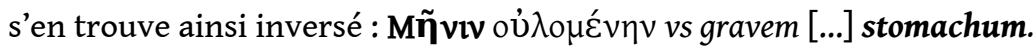

\section{Les aigreurs d'Achille et Ulysse l'équivoque} $\mu \tilde{\eta} v 1 \varsigma$ grecque est rendue en latin par le terme stomachus. Déjà A. Kiessling et R. Heinze ont souligné que ce mot appartenait à l'Umgangssprache : s'il est approprié au registre des satires, il a été refusé par la poésie ${ }^{39}$. Plus tard, R. G. M. Nisbet et M. Hubbard ne manquent pas à leur tour de relever le caractère prosaïque du terme ${ }^{40}$. En effet, le premier sens de stomachus est «estomac», puis «bonne ou mauvaise digestion». S'il peut signifier effectivement "colère», ce n'est que par un glissement de sens progressif : de la bonne ou mauvaise digestion découle la bonne ou mauvaise humeur et, partant, l'irritabilité. Nous sommes alors bien loin de la funeste colère du Péléide, sujet de l'Iliade! Ces éléments nous invitent, dans un premier temps, à réfléchir à la traduction de stomachus dans l'ode ${ }^{41}$. Rares sont les traducteurs qui cherchent à rendre le sens prosaïque de ce terme. Quant aux commentateurs de l'ode qui font remarquer l'incongruité de stomachus, aucun ne propose une traduction rendant la trivialité et l'ambivalence du terme ${ }^{42}$. Pour conserver le double sens de stomachus, et l'image que donne le poète de la colère d'Achille qui n'a pas bien digéré l'enlèvement de sa captive par Agamemnon, je propose le mot « aigreur », qui peut désigner en français le malaise aussi bien physique qu'émotionnel.

Il paraît indispensable, dans un deuxième temps, de faire une recherche d'occurrences pour mesurer l'effet de surprise produit et expliquer les raisons de cette traduction volontairement maladroite. Notons, pour commencer, que l'usage de stomachus pour désigner la colère n'est pas rare. Son emploi assez fréquent chez Cicéron nous donne l'occasion d'apprécier pleinement la manière dont ce terme était connoté dans un latin classique: stomachus est employé de manière récurrente dans les lettres $\mathrm{Ad}$ familiares pour désigner une colère liée à une dispute d'ordre privé ou une mauvaise humeur ${ }^{43}$, ou bien, dans le cadre de désaccords politiques, une rancœur qui pèse sur l'estomac de l'orateur ${ }^{44}$.

17 Pour ce qui concerne les Odes, on ne trouve qu'une seconde occurrence du terme : en 1, 16, 16, Prométhée a mis la force du lion in stomacho nostro. Même si le terme apparaît dans un contexte où il est question de force, de courroux, ici stomachus désigne non un sentiment, mais le siège (la poitrine ou le ventre, plus largement l'abdomen) de la colère, désignée au vers suivant par le substantif ira, par lequel on traduit traditionnellement la $\mu$ ñvıৎ homérique. C'est d'ailleurs le terme ira qui est utilisé dans le reste du recueil pour évoquer la terrible colère de Thyeste ou de Junon (grauis ira, 3, $3,30)$, et l'adjectif iracundus qui est employé pour décrire la flotte d'Achille $(1,15,33)$. Rappelons à cet égard un passage de l'Art poétique où Horace invite l'apprenti auteur à décrire les personnages tels qu'ils ont été façonnés par la tradition: Achille en particulier doit rester impiger, iracundus, inexorabilis, acer (Ars 121) ${ }^{45}$.

18 Comme dans les Odes, le terme est un hapax dans l'Énéide où, note Servius ${ }^{46}$, il est utilisé

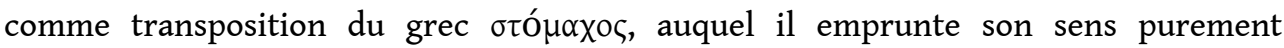
anatomique pour désigner la gorge, guttur en latin : en 9, 691, Turnus abat Antiphatès en lançant et fichant un javelot dans la poitrine, stomacho, de son ennemi ${ }^{47}$. Pour désigner la colère, Virgile use évidemment du terme plus traditionnel ira. Relisons par

Interférences, 9 | 2016 
exemple la manière dont il décrit, dans l'Énéide, la colère de son héros éponyme et celle de Turnus (A. 12, 527-528) :

fluctuat ira intus, rumpuntur nescia uinci

pectora $[. .$.

«La colère bouillonne en eux, leurs cœurs qui ne savent pas être vaincus se rompent ».

Contrairement à Virgile, qui utilise deux termes pour désigner la colère de ses héros, Horace parvient, avec stomachus, à renvoyer, en un seul mot et de manière triviale, au sentiment de colère lui-même (ira) et au siège de celui-ci (pectora). Par ailleurs, remarquons que les deux poètes expliquent la colère des héros par le truchement du même adjectif nescius, construit dans les deux cas avec un infinitif : cedere nescii et nescia uinci ${ }^{48}$. Alors que le poète de Mantoue fait de la colère de ses héros épiques l'origine de leur force guerrière et de leur capacité à vaincre, chez Horace la colère provient d'une incapacité à céder dans le conflit et à supporter la frustration ${ }^{49}$.

Si le terme stomachus est quasiment absent du recueil des Odes, il semble davantage appartenir au monde des Satires, où Horace l'emploie de manière récurrente. Huit fois sur neuf, le mot garde alors son sens propre d'«estomac» et apparait dans des contextes triviaux évoquant les excès de la table et une mauvaise digestion. Le livre 2 des Satires, par exemple, compte huit occurrences ${ }^{50}$ de ce terme entendu dans son sens le plus trivial de "ventre, estomac, digestion ». La satire 2, en particulier, établit une liste des maux qui peuvent troubler le stomachus : ce dernier est d'abord latrans (v. 18) ou ieiunus (v. 38) en l'absence de nourriture, puis, après un repas copieux, il est aeger (v. 43), et enfin la bile et la pituite y portent le trouble (v. 75). Pour ce qui concerne la neuvième occurrence du terme dans les Satires, Horace l'emploie pour qualifier la mauvaise humeur de Davus, son esclave, qui se montre mécontent devant les remontrances de son maître ${ }^{51}$. Horace opère donc une greffe d'un terme trivial, appartenant davantage au registre des Satires, dans un contexte épique.

L'expression cursus duplicis per mare Vlixei, censée résumer cette fois le sujet de l'Odyssée au vers 7, appelle le même type d'analyse. On peut d'abord hésiter sur le cas de la forme duplicis : on sera tenté dans un premier temps d'y voir un accusatif pluriel, expansion du nom cursus. Mais il est plus vraisemblable qu'il constitue en réalité un génitif singulier qualifiant Ulixei et traduisant ainsi en latin l'épithète homérique attaché à la

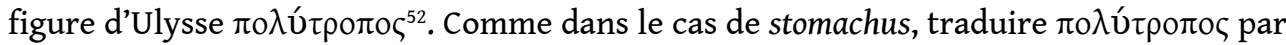
duplex peut sembler maladroit à bien des égards. À première vue, l'emploi du terme ne choque pas. Ses sonorités d'abord le font entrer parfaitement en résonance avec le nom d'Ulysse : duplicis Ulixei. Par ailleurs, le TLL donne comme synonymes à duplex les adjectifs mendax, insincerus, simulator ${ }^{53}$, qui conviennent parfaitement à la figure

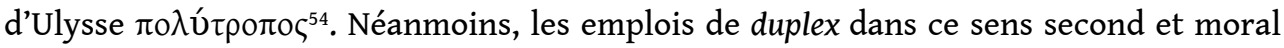
sont très rares. C'est surtout son sens concret - distributif, multiplicatif - que le terme revêt dans le corpus latin. Horace lui-même ne l'emploie pas dans son sens second : les quelques occurrences du terme appartiennent aux Satires, où l'adjectif sert à désigner soit une branche de figuier qui porte deux fruits ${ }^{55}$, soit une sauce élaborée à partir de deux ingrédients ${ }^{56}$. Pour le sens second, moral ou psychologique, le TLL renvoie uniquement aux comédies de Plaute où duplex, utilisé à deux reprises, décrit, dans un sens à la fois concret et abstrait, la langue fourchue des serpents ${ }^{57}$, et au carmen 68 de Catulle où il désigne la déesse d'Amathonte ${ }^{58}$, Vénus, qui est double, fourbe, car elle provoque aussi bien la joie que les pleurs ${ }^{59}$. 
L'effet de décalage produit par l'emploi de stomachus et de duplex repose ainsi sur un même procédé : Horace s'amuse à utiliser des termes très concrets dans une acception morale et psychologique rare, voire triviale, pour évoquer les sujets des épopées homériques. Encore une fois, l'effet produit par ce décalage est humoristique. Mais le poète cherche-t-il uniquement à être plaisant, à provoquer la surprise de son lecteur? En sapant la solennité homérique, Horace cherche-t-il à parodier l'épopée?

\section{Parodie ou jeu?}

Il faut revenir en effet sur le terme "parodie", qui apparaît dans de nombreux commentaires sans que la notion et sa portée soient pour autant expliquées de manière satisfaisante. Horace adopte-t-il une attitude parodique ? Dès lors, de qui ou de quoi se moque-t-il ? On peut écarter l'hypothèse que le poète se moque ici d'Agrippa, dont les exploits sont - non sans malice toutefois - rapprochés des terribles aigreurs d'Achille. En revanche, C.F. Ahern affirme qu'en choisissant des traductions volontairement décalées de termes homériques en 1, 6, le but d'Horace est de parodier les auteurs homérisants de son époque. C'est une hypothèse très séduisante, mais malheureusement C. F. Ahern n'en fait pas la démonstration pour l'emploi de stomachus et de duplex. En suivant son intuition, on peut supposer qu'Horace emploie ces deux termes pour se moquer en particulier des efforts des poètes homérisants pour imiter ou transposer - avec plus ou moins de succès - le langage homérique dans la Rome d'Auguste. Ainsi stomachus, dont Servius nous dit qu'il est un emprunt au grec $\sigma \tau o ́ \mu \alpha \chi \circ \varsigma$, pourrait illustrer une tentative pédante, mais maladroite, d'incorporer un hellénisme dans la langue latine pour donner un tour homérique à un récit épique.

De la même manière, on pourrait voir dans duplex l'effort raté d'un piètre poète qui, en voulant rendre la duplicité du héros de l'Odyssée par un terme latin aux consonances grecques, aurait choisi duplex, proche du grec $\delta i \pi \lambda \circ \tilde{v} \varsigma$ ou de $\delta i ́ \pi \lambda \alpha \xi$. L'erreur consisterait en ce que ces termes grecs, récurrents chez Homère, ne sont jamais employés chez l'aède dans un sens moral ("fourbe») mais uniquement avec un sens distributif (« deux, double »). Ils servent en effet, dans l'Iliade et l'Odyssée, à qualifier un morceau d'étoffe double ${ }^{60}$, ou la double épaisseur d'une cuirasse ${ }^{61}$, ou encore la double couche de graisse dont on recouvre les restes d'un défunt déposés dans l'urne funéraire ${ }^{62}$. L'adjectif $\delta ı \pi \lambda_{0} \tilde{\varsigma^{63}}{ }^{63}$, associé à $\gamma \lambda \tilde{\omega} \sigma \sigma \alpha$, est en revanche utilisé par Hécube pour évoquer la fourberie d'Ulysse dans les Troyennes d'Euripide ${ }^{64}$. On peut dès lors se demander si le jeu érudit d'Horace ne consisterait pas également à modifier Homère par le truchement d'Euripide. Dans tous les cas, la traduction dans l'ode par le terme duplex reste (volontairement) maladroite car, en latin, le sens moral de l'adjectif demeure rare.

Si Horace se moque des poètes homérisants de son époque, il me semble néanmoins, pour reprendre les mots de $\mathrm{D}$. West ${ }^{65}$, que la première cible de l'humour du poète, c'est lui-même. En effet, Horace se parodie en se mettant plaisamment en scène dans la persona de l'humilis poeta qui ne parvient pas à s'élever au rang de l'épopée. À l'aide de stomachus et duplex, le poète montre, comme une théorie en acte, non pas pourquoi il ne peut pas faire de l'épopée, mais pourquoi il ne doit pas en composer: le fait même d'évoquer des sujets graves l'amène à commettre de grossières maladresses. Il pourrait effectivement ternir (deterere, v. 11) les exploits d'Auguste et d'Agrippa s'il s'essayait à en faire le récit. Encore une fois, le lecteur averti ne sera pas dupe de cette apparente 
autodérision. L'emploi de stomachus et de duplex ne témoigne-t-il pas au contraire de la capacité du poète à jouer avec le langage épique?

Selon C. F. Ahern, la parodie se double bien d'un jeu littéraire destiné à ravir Varius, dédicataire de l'ode et friand d'amusettes philologiques. Le terme stomachus serait en

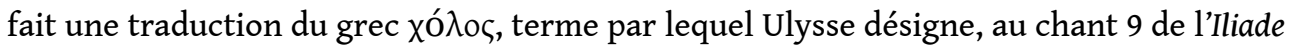

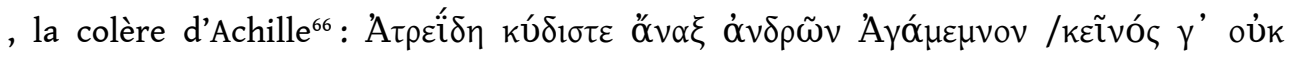

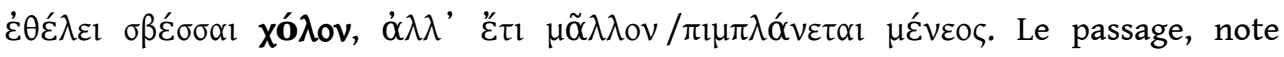
C.F. Ahern, emploie deux mots différents pour désigner la colère, dont xó qu'Horace a pu traduire par le terme latin stomachus. Toutefois, si Horace corrige plaisamment Homère par Homère lui-même, et procède à une correction alexandrine, ce n'est sans doute pas en jouant uniquement sur cette citation. En effet, le terme

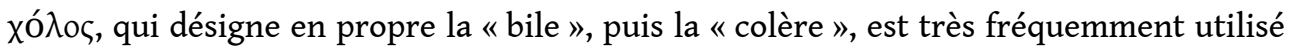
dans l'Iliade, et même bien plus employé pour désigner le sentiment de colère que la célèbre $\mu \tilde{\eta} v ı$. On compte 18 occurrences de cette dernière, contre 39 , soit plus du

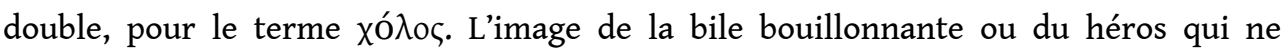
parvient pas à digérer sa colère est en effet récurrente dans l'Iliade, notamment au chant 1 , lorsqu'il est question des disputes et de la colère d'Agamemnon et d'Achille ${ }^{67}$. Par ce jeu avec le modèle homérique, Horace ne témoigne pas seulement de son envie d'être plaisant à son lecteur ou de sa sensibilité alexandrine: derrière cet apparent badinage, derrière l'emploi de duplex et de stomachus, se révèle toute l'habileté d'Horace.

Si la dimension ludique est évidemment très présente, les préoccupations du poète ne sont sans doute pas purement littéraires: le jeu, chez Horace, revêt également un caractère plus sérieux. Le poète de Venouse ne dit-il pas lui-même, dans l'Art poétique ${ }^{68}$, que la poésie a avant tout un but moral ? Comme ferox, désignant l'attitude des soldats d'Agrippa, il faut relire les termes utilisés pour caractériser les sujets héroïques avec cette dimension morale à l'esprit. Si Aristote fait remarquer que l'ethos d'Achille est changeant et instable, ici la brièveté de l'allusion (grauem stomachum Pelidae cedere nescii) en fait un personnage-type, unidimensionnel, qui modélise un comportement: l'irascibilité, l'emportement. Horace puise là parmi les topoi de la morale grecque et romaine ${ }^{69}$. Le choix du terme stomachus et l'expression cedere nescii contribuent encore davantage à présenter le comportement d'Achille de manière négative. Évoquer le Péléide pose peut-être au poète un problème aussi bien littéraire que moral car son comportement est contraire aux valeurs romaines, notamment la temperentia. Le héros de l'Iliade se signalera d'ailleurs deux odes plus loin pour son comportement négatif. En 1,8, Horace rappelle en effet l'épisode d'Achille à Scyros, et condamne ainsi sa mollestia qui en fait un contre-modèle pour la jeunesse romaine, invitée à revenir à la virtus militaris. Quant à Ulysse, sa duplicité topique, soulignée ici par l'incongru duplex, rappelle qu'il est depuis Homère un personnage fourbe, qui agit par ruse, en somme un ennemi de la probitas, mais surtout de la fides, vertus cardinales à Rome, qui figurent dans le Carmen Saeculare en tête du cortège des vertus regagnant Rome après les guerres civiles. Enfin, l'adjectif saeuus, utilisé pour qualifier la maison de Pélops au vers 7, renvoie à la saeuitia et s'oppose ainsi à une valeur romaine importante qui s'était imposée à la fin de la République avec César, et plus encore sous le principat d'Auguste : la clementia. Notons que les deux dernières vertus évoquées - fides et clementia - étaient présentes sur le clipeus uirtutis offert par le sénat à Auguste en 27 av. J.-C. et qui représentait non seulement une gratiarum actio, mais aussi un programme moral: 
c'était une manière d'exhorter le prince et le peuple romain à cultiver les vertus inscrites sur le bouclier. Ainsi, les figures d'Achille, d'Ulysse et de Thyeste ne sont pas seulement l'incarnation de genres ou de traditions littéraires, elles modélisent aussi des comportements. Tout comme Énée d'ailleurs, qui n'est pas seulement un Ulysse ou un Jason romain mais qui incarne et modélise dans l'Énéide la pietas romaine. Dès lors, la question sous-jacente dans l'ode n'est pas seulement littéraire (peut-on vraiment faire à l'époque d'Auguste de l'épopée en des formes héritées d'Homère ?), elle est aussi morale: les figures de l'épopée sont-elles réellement des modèles pour les héros contemporains modernes (Agrippa, Auguste)? Constituent-elles des figures exemplaires adéquates pour les Romains, appelés à refonder moralement Rome sous la conduite du Prince?

\section{Grauis et duplex : des termes programmatiques?}

Loin d'être incapable de se mesurer à Homère ou de faire de l'épopée comme Virgile, le poète montre au contraire dans l'ode 1,6 sa pleine maitrise de ses modèles et du langage épiques, qu'il est capable de déconstruire, non pour les rejeter ou les parodier, mais au contraire pour les reconstruire, se les approprier et les réinvestir.

\section{Grauis vs leuis}

29 Les recherches d'occurrences du terme stomachus ont amené à observer un décalage, une tension d'ordre générique entre le terme trivial approprié aux satires et son environnement d'insertion. L'adjectif grauis, qui porte au vers 5 sur stomachus et qui

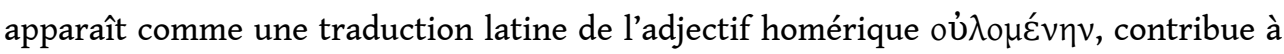
accentuer encore la rupture de ton perceptible dans l'expression stomachus Pelidae. En effet, le caractère grave, pesant et solennel de grauis entre en opposition avec la trivialité de stomachus. En traduisant grauis par "terrible", on parviendra à rendre deux effets sans doute voulus par Horace : « la terrible aigreur du Péléide » fera sentir tout à la fois qu'il s'agit ici d'une transposition maladroite de l'expression grecque et qu'Horace cherche à créer un effet de choc entre les deux termes latins. On pourra aussi choisir de jouer comme Horace sur l'ambivalence du mot et de lui donner son sens littéral et matériel, celui de «lourd, pesant»: l'image amusante renvoyée alors par l'expression est que l'affront subi par Achille lui pèse littéralement sur l'estomac.

S'il participe encore au jeu de contrastes ménagé par Horace, l'adjectif grauis a aussi et surtout une portée singulière à Rome, et particulièrement dans un contexte de recusatio : Horace utilise là un terme programmatique qui renvoie à Catulle et aux élégiaques, chez qui la grauitas désigne l'ampleur des sujets graves opposée à la leuitas des genres mineurs. L'adjectif qualifiant le stomachus d'Achille ne se contente pas ainsi de traduire

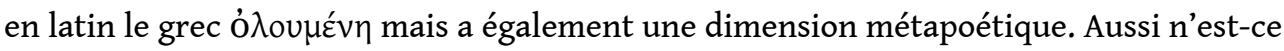
pas tant la colère d'Achille qui est grauis que le sujet de l'Iliade lui-même: ce dernier, tout comme les res gestae d'Agrippa, est un sujet trop lourd pour le poète, car il lui demande une certaine grauitas à laquelle Horace affirme ne pouvoir s'élever.

Cette image que renvoie grauis d'un sujet trop lourd pour les épaules du poète est d'ailleurs donnée littéralement dans un passage de l'Art poétique où le poète revendique un idéal d'aequitas, d'équilibre et de proportion: chaque poète doit savoir quelle matière il est capable d'assumer (v. 38-41) : 
Sumite materiam uestris, qui scribitis, aequam

uiribus et uersate diu quid ferre recusent,

quid ualeant umeri [...]

"Vous qui écrivez, prenez une matière proportionnée à vos forces et soupesez

longuement ce que vos épaules peuvent ou non porter».

Contrairement à l'idée véhiculée par culpa ingenii au vers 12 de l'ode 1, 6, ici la réussite de l'entreprise poétique dépend moins des qualités naturelles du poète (ingenium, natura) que de sa capacité à adapter ses forces (vires) à son projet littéraire, à la matière (materia) qu'il veut traiter. Cette notion d'équilibre est en outre mise en valeur par l'hyperbate entre materiam et aequam, qui souligne ainsi aequam en le rejetant à la fin du vers.

L'idée selon laquelle grauis est utilisé dans l'ode 1,6 dans un emploi programmatique qui renvoie à l'antithèse grauitas/leuitas est par ailleurs corroborée à la fin du texte par l'utilisation de l'adjectif leues, ultime mot de la pièce (v. 17-20) :

Nos convivia, nos proelia uirginum

Sectis in iuuenes unguibus acrium

Cantamus, uacui siue quid urimur

Non praeter solitum leues.

« Nous ce sont les banquets, nous ce sont les combats des jeunes filles bataillant contre les jeunes hommes de leurs ongles coupés que nous chantons, quand nous sommes oisifs ou que nous brûlons de quelque feu, légers, comme à l'ordinaire. »

Par opposition à la colère d'Achille, sujet noble et ample, ressortissant à la grauitas, les conuiuia et les proelia uirginum sont des sujets qui réclament de la leuitas. Horace reconstitue ainsi l'opposition paradigmatique grauitas/leuitas, qu'Ovide évoquera de manière plus directe dans ses Amours. Souvenons-nous en effet des vers 36 et 41 de l'élégie $3,1:$ an numquam non grauis esse potes [...] sum leuis, et mecum leuis est, mea cura, Cupido. Dans l'ode 1, 6, les termes de l'opposition sont très nettement mis en valeur par leur disposition: grauis et leuis encadrent les strophes 2 à 5 du poème, accentuant encore la symétrie de ces dernières (v. 5-8 et 17-20):

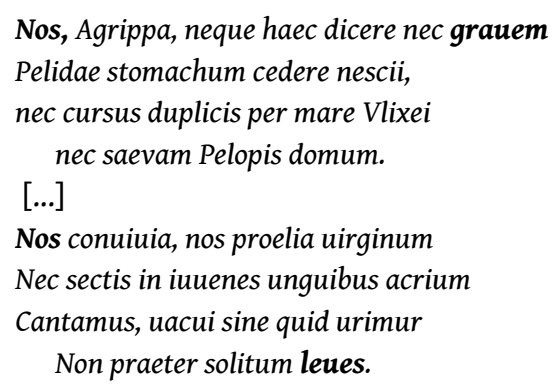

La reprise, à l'initial au vers 17, de nos, déjà employé au vers 5, avec l'effet de rupture qu'il produit avec ce qui précède (voir ci-dessus), crée un écho entre les deux strophes qui évoquent d'une part les sujets qu'Horace ne veut pas chanter et d'autre part ce qu'il a choisi de célébrer. Ce jeu avec les pronoms, qui permet d'opposer nettement et de répartir les thèmes épiques et les thèmes érotiques, se trouve déjà chez Anacréon et sera repris par Horace dans la recusatio de l'ode $2,4^{70}$. Pour évoquer sa propre poétique, le poète latin n'évoque donc pas seulement des thèmes de la lyrique grecque, mais utilise aussi ses procédés ${ }^{71}$. Les termes grauis et leuis qui apparaissent dans ces deux strophes conceptualisent ces différences d'inspiration. La place qui les met nettement en valeur confirme cette idée : alors que grauis apparaît en contre-rejet de la strophe 2, leues est rejeté au dernier vers du poème. 
mme le font les poètes élégiaques pour qui militat omnis amans ${ }^{72}$, Horace s'amuse par ailleurs à détourner, dans cette dernière strophe consacrée aux sujets leues, le vocabulaire de la guerre. Notons tout d'abord l'expression in iuuenes acrium. Elle fait écho à la description de Mars dans l'ode 1, 2, où le dieu de la guerre est acer in hostes. L'expression proelia uirginum peut également surprendre. Le terme proelia était plus attendu pour évoquer les exploits d'Agrippa ou les combats de César, respectivement désignés avec imprécision par le démonstratif haec (v. 5) et métonymiquement par le truchement du terme laudes (v. 11). Ici les proelia Caesaris - expression qu'on trouve par ailleurs en 2,12,10 - sont remplacés par les proelia uirginum, combats d'un genre bien différent. Néanmoins, si tous ces éléments renvoient évidemment à l'univers de l'élégie où l'on préfère évoquer les combats d'alcôve que ceux de César, le poète ne prend pas exactement la posture de l'amant élégiaque. C'est plutôt l'univers du banquet que construit Horace avec la mention explicite des conuiuia et la miniature alexandrine esquissée dans les vers 16-17 :

Nos conuiuia, nos proelia uirginum

a

Sectis IN IUUENES unguibus acrium

b $b \quad a$

La disposition des mots souligne la dimension érotique de ces jeux: les iunenes se trouvent au centre d'une structure en chiasme qui suggère la proximité, le corps à corps, et reproduit le mouvement lascif des jeunes filles, leur enlacement et peut-être même leur ronde autour des jeunes garçons. Serait-il dès lors abusif de penser que la métrique souligne ici non seulement le caractère érotique de ces proelia, mais aussi leur dimension chorétique? Notons, à cet égard, que la miniature alexandrine esquissée dans ces vers annonce celle peinte par Horace dans la recusatio de l'ode 2,12, qui évoque la danse à laquelle se livre Lycimnia (v. 16-20) :

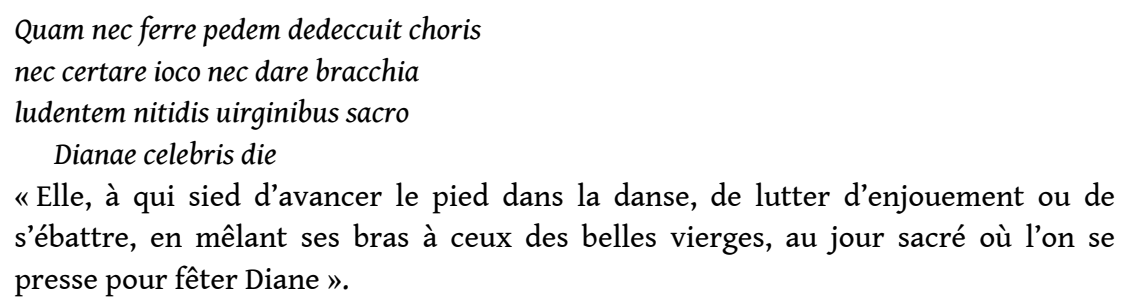

Nous retrouvons dans ces vers, comme en 1, 6, le vocabulaire de la guerre qui se trouve détourné (ferre pedem, certare), la mention des vierges (uirginibus), la dimension de jeu ${ }^{73}$ (ioco, ludentem), et les gestes (dare bracchia), ici plus précisément décrits.

Ce mouvement, qui conduit le poète à passer de l'évocation d'une matière grave (grauis), qu'il rejette, à celle qu'il choisit, et qui est leuis, structure les odes 1, 6 et 2, 12, mais également la recusatio de l'ode $2,1:$ Horace évoque d'abord les guerres civiles, des sujets qu'il qualifie de graves (graves, v. 3), pour revenir, dans le dernier vers de l'ode, à un mode et un plectre plus légers (leuiore plectro, v. 40). Ainsi, comme dans 1, 6, la leuitas lyrique répond à la grauitas épique, et s'impose finalement face à elle en se posant comme dernier mot de l'ode. autre opposition: tenuis/grandis, évoquée explicitement au vers 9 de la recusatio 1, 6 . Cette fois, les deux termes antithétiques ne sont pas séparés mais au contraire juxtaposés, pour créer un effet de choc (v. 9-12): 
[nec] conamur, tenues grandia dum pudor

inbellisque lyrae Musa potens uetat

laudes egregii Caesaris et tuas

culpa deterere ingeni

«Non, nous ne tentons pas, faible que nous sommes, ces sujets sublimes car la pudeur et la muse qui a tout pouvoir sur notre lyre pacifique nous interdisent de

ternir les louanges du grand César et les tiennes, faute de génie ».

(tenuis) pour les grands sujets épiques, convoque l'argument du défaut de compétence. Les deux termes antonymes tenues et grandia sont volontairement juxtaposés au vers 9 pour créer un effet de choc, encore renforcé par la coupe qui les sépare, mettant ainsi en évidence le déséquilibre qui existe entre la modestie d'Horace et l'ampleur des thèmes épiques. Par ailleurs, l'opposition paradigmatique tenuis/grandis est généralement employée par les poètes élégiaques pour opposer élégie légère (tenuis) et épopée grave (grandis ou grauis). Le terme tenuitas est en fait une traduction latine du terme $\lambda \varepsilon \pi \tau$ ótnఢ, employé par Callimaque ${ }^{74}$ pour désigner la finesse, la délicatesse de son style, en opposition au registre épique. La tenuitas, dont se réclame le poète, appartient également au vocabulaire de la rhétorique latine et des genera dicendi, où elle désigne un style simple et sans ornement.

L'analyse de l'expression grauis stomachus Pelidae montre une fois encore que les détournements $d u$ vocabulaire homérique ne sont pas seulement un jeu ou une parodie: ils sont réinvestis par Horace qui en fait, dans la recusatio, des indices programmatiques et leur donne une dimension méta-poétique. L'ode est ainsi traversée par des oppositions paradigmatiques, opposant genre épique et genre mineur. À l'opposition frontale de grandis/tenuis, et à celle plus subtile de grauis/leuis, il faut peutêtre en ajouter une troisième : duplex/simplex.

\section{Duplex vs simplex?}

À la lumière des enjeux que revêt l'utilisation de l'adjectif grauis, on pourra s'interroger à nouveau sur le choix de l'adjectif duplex. Le terme renvoie certes à la rouerie

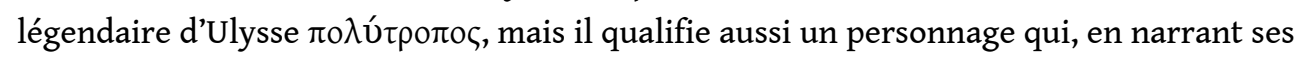
errances à la table l'Alcinoos dans l'odyssée, est devenu un double de l'aède. L'expression utilisée par Horace pour résumer l'odyssée, cursus per mare, peut par ailleurs être interprétée comme une périphrase désignant l'épopée. Aussi le choix de duplex pour qualifier une figure de poète épique ne relève peut-être pas uniquement d'une traduction volontairement maladroite d'un terme homérique. On connait la valeur programmatique qu'aura cet adjectif chez Ovide $^{75}$, et peut-être chez Horace. Aussi, comme grauis et grandis, le terme duplex revêt-il une dimension métapoétique.

Même si le terme duplicitas n'existe pas dans la langue latine avant les Pères de l'Église, la notion est présente dans l'œuvre d'Horace à travers son antonyme, la simplicitas. Cette notion est fondamentale chez le poète de Venouse : elle représente pour lui un idéal aussi bien moral que poétique. Rappelons à cet égard les passages de l'Art poétique où il revendique clairement et à plusieurs reprises un idéal de simplicitas, de simplicité, d'unité et d'harmonie, en littérature. Dans la première partie de l'épître, Horace invite celui qui veut écrire à cultiver la simplicitas en traitant un sujet simple et unique. Il lui livre cette maxime devenue célèbre (Ars 23) :

Denique sit quod uis, simplex dumtaxat et unum 
« Enfin, que tout ce que tu veux créer soit seulement simple et un ».

Horace se fait ici l'écho du précepte platonico-aristotélicien de l'unité en art. La redondance simplex... unum permet non seulement d'insister sur l'exigence de simplicité, mais il s'agit aussi et surtout, comme le note O.C. Brink, de faire écho à l'expression d'Aristote Ěv koì ǒ $\lambda o v$. Néanmoins, simplex n'est pas un équivalent strict de ǒ $\lambda$ ov, qui correspondrait davantage au latin totum. Avec cette petite variation, l'accent est davantage mis chez Horace sur l'exigence non d'unicité, mais d'invariabilité. O.C. Brink note à cet égard que simplex vient préciser le terme unum, trop vague et abstrait, et signifie « ce qui ne varie pas ${ }^{76}$ ».

La simplicitas interviendra à nouveau un peu plus loin dans l'Art poétique. Aux vers 203-204, Horace regrette la simplicité de la tibia d'autrefois :

Tibia non, ut nunc, orichalco uincta tubaeque

aemula, sed tenuis simplexque [...]

«La flûte n'était pas, comme maintenant, assemblée à l'aide de cuivre blanc, ni la

rivale de la trompette, mais elle était frêle et simple [...]».

Le terme simplex est juxtaposé à l'adjectif tenuis, qui apparaissait au vers 9 de notre ode et dont nous avons vu la valeur programmatique. La simplicitas de la flûte est ici étroitement associée à la tenuitas. Cette flûte légère, ténue, rappelle par ailleurs le mince pipeau (tenuis avena) - lui aussi programmatique du genre pastoral - sur lequel s'exerce Tityre à l'ouverture des Bucoliques de Virgile $(1,2)$.

Cette notion de simplicitas intervient aussi dans les Odes. Après l'ode 1, 37 d'inspiration civique et au ton solennel, où il est question de la victoire d'Actium, Horace réclame, dans l'ode 1, 38, une couronne de simple myrte (simplici myrto, v. 5). Cet objet humble, sur lequel se referme le premier livre des Odes, est destiné à accompagner le banquet simple et frugal auquel Horace convie son esclave, après l'appel public au lectisterne, le célèbre Nunc est bibendum. La couronne renvoie évidemment au choix d'une vie modeste, passée dans l'intimité d'une villa, par opposition aux fastes des célébrations publiques. Mais plus largement, la simplicité de l'objet symbolise aussi la simplicitas du ton désormais adopté, par opposition à celui que réclamait, dans l'ode précédente, la célébration des victoires du prince.

À cette hypothèse on pourra néanmoins faire une objection : l'esthétique d'Horace n'a en réalité pas grand-chose de simplex. L'habileté du poète à jouer avec ses modèles, la complexité de la recusatio que cet article a essayé de montrer et d'éclairer en sont une parfaite illustration. Par ailleurs, l'esthétique horatienne n'est pas leuis ou tenuis, dans la mesure où elle ne chante pas seulement les banquets et les combats d'alcôve, comme l'affirme le poète dans la dernière strophe de la recusatio. L'ode 1, 37 ou les Odes romaines, pour ne prendre que des exemples très célèbres, montrent bien que la poésie d'Horace est capable de s'intéresser à des sujets plus graves, comme les victoires militaires du prince ou la restauration des valeurs romaines après les guerres civiles. Les oppositions paradigmatiques qui traversent la recusatio 1,6, grauis/leuis, grandis/ tenuis et peut-être duplex/simplex, ne sont évidemment pas à prendre au pied de la lettre : la recusatio ne fonctionne pas comme une manière d'opposer frontalement les valeurs que le poète rejette catégoriquement, ou remet à un tiers, à celles qu'au contraire il embrasse et revendique. Ces oppositions ne sont pas non plus simplement les éléments devenus topiques d'une mise en scène conventionnelle du poète lyrique ou élégiaque dans la persona de l'humilis poeta. Toutes ces notions évoquant les genres graves ou les genres légers permettent au poète de créer une mise en tension, d'exhiber 
une interrogation au sujet des genres littéraires, objets d'inquiétudes sans précédent à l'époque d'Horace.

\section{Conclusion}

L'aveu de modestie, le regrettable défaut de compétence, l'interdiction de la muse, la figure d'un poète leuis incapable de s'élever à la grauitas du genre noble: l'ode 1, 6 contient tous les topoi constitutifs du procédé de la recusatio. Évidemment, le lecteur n'aura pas de mal à reconnaître une modestie de convention. Dès les premiers vers, le poète montre en effet sa maîtrise du genre noble en offrant le synopsis d'une épopée contemporaine qui mobilise avec habileté quelques procédés épiques. Dans un second temps, le poète, feignant d'être bien maladroit, ne se prive pas, comme nous l'avons montré, de jouer sur l'ambiguïté, le détournement plaisant, la correction philologique. Néanmoins, si Horace cherche par ces décalages volontaires à provoquer la surprise de son lecteur, ce n'est pas tant pour lui être plaisant que pour obtenir de lui toute son attention. Car derrière ce badinage se cache en réalité les indices trahissant un (en)jeu bien plus sérieux. Les expressions grauis stomachus Pelidae et duplex Ulixes n'illustrent pas l'incapacité, ni même l'ironie du poète face à l'épopée : en entrant dans la lyrique, la colère d'Achille ou la figure d'Ulysse l'équivoque, devenus les objets d'un jeu habile et érudit, manifestent au contraire qu'Horace a une connaissance et une maîtrise parfaites du langage et des codes épiques. En créant des décalages, ces expressions deviennent en outre les instruments d'une mise en tension générique et établissent des oppositions paradigmatiques manifestes (grauis/leuis) ou moins visibles (duplex/ simplex). Ainsi ce qui peut apparaître à première vue comme un jeu est en réalité une manière pour le poète de s'interroger aussi bien sur la démarche consistant à faire de l'épopée à l'époque du prince que sur sa propre poétique et sur le procédé même de la recusatio.

\section{BIBLIOGRAPHIE}

\section{Textes anciens}

Horace, Épîtres suivi de l'Art poétique, texte établi et trad. par F. VILLENEUVE, CUF, Paris, Les Belles Lettres, 2014 [1934].

Quinti Horatii Flacci Opera omnia. The Works of Horace. I, The Odes, Carmen Saeculare, and Epodes, with a commentary by E. C. WICKHAM, Clarendon Press Series, Oxford, Clarendon Press, 1874.

Horace, Odes and Epodes, ed., with introd. and notes by P. SHOREY, Boston, B. H. Sanborn, 1898.

Q. Horatius Flaccus. I, Oden und Epoden, erklärt von A. KIESSLING, 6. Aufl. erneuert von R. HEINZE, Berlin, Weidmann, 1917. 
Horace Odes. I, Carpe diem, transl. with an introd. and notes by D. WEST, Oxford, Clarendon Press, 1995.

Horace, Odes et Épodes, texte établi et trad. par F. VILLENEUVE, CUF, Paris, Les Belles Lettres, 2002 [1929].

Horace, Odes and Epodes, ed. and transl. by N. RUDD, The Loeb Classical Library. Latin Authors 33, Cambridge, Harvard University Press, 2004.

Virgil, Aeneid. Book IX, ed. by P. HARDIE, Cambridge Greek and Latin Classics, Cambridge, Cambridge University Press, 1994.

\section{Études modernes}

AHERNS C. F. Jr. 1991, « Horace's Rewriting of Homer in “Carmen” 1. 6 », CPh 86, 4, p. 301-314.

BRINK C. O. 1971, Horace. II, The Ars poetica, Cambridge, Cambridge University Press.

CAIRNS F. 1995, « M. Agrippa in Horace Odes 1.6 », Hermes 123, p. 211-217.

CALAME C. 1994, « Les Hymnes homériques. Modalités énonciatives et fonctions », Mètis 9, 1, p. 391-400.

CALBoli G. 2004, « The Schemata $\lambda \dot{\varepsilon} \xi \varepsilon \omega \varsigma$ : A Grammatical and Rhetorical Tool », Rhetorica 22, p. 252-256.

CAVARZERE A. 1996, Sul limitare: il motto e la poesia di Orazio, Testi e manuali per l'insegnamento universitario del latino 47, Bologne, Pàtron.

CITRONI M. 2000, « The Memory of Philippi in Horace and the Interpretation of Epistle 1.20.23 », CJ 96, p. 27-56.

COMMAGER S. 1962, The Odes of Horace. A Critical Study, New Haven - London, Yale University Press. CORBEILl A. 2015, Controlling Laughter. Political Humour in the Roman Republic, Princeton, Princeton University Press.

DANGEL J. 2001 (éd.), Le poète architecte. Arts métriques et art poétique latins, Bibliothèque d'études classiques 24, Louvain, Peeters.

DAVIS G. 1987, « 'Quis . . digne scripserit?' The topos of Alter Homerus in Horace Carm. I.6 », Phoenix 41, p. 292-295.

FRAENKEL E. 1957, Horace, Oxford, Clarendon Press.

GALINSKY K. 1996, Augustan Culture. An Interpretative Introduction, Princeton, Princeton University Press.

GANTÀR K. 1986, « La seconde strophe asclépiade dans les Carmina I-III d'Horace », in Hommages à Jozef Veremans, Latomus 193, Bruxelles, Latomus, p. 125-136.

HARDIE P. 2002, Ovid's Poetics of Illusion, Cambridge, Cambridge University Press.

HOFFER S. 2007, « Cicero's ‘Stomach': Political Indignation and the Use of Repeated Allusive Expressions in Cicero's Correspondence ", in R. MORELLO, A. MORRISON (ed.), Ancient Letters. Classical and Late Antique Epistolography, Oxford, Oxford University Press, p. 87-106.

KOVACS D. 2006, « Double Trouble: "Duplicis" at Horace, "Odes" 1.6.7 and the Limits of Ambiguity », ICS 31/32, p. 55-74. 
LA PENNA A. 1963, Orazio e l'ideologia del principato, Saggi 332, Turin, Einaudi.

LE DOZE P. 2014, Le Parnasse face à l'Olympe. Poésie et culture politique à l'époque d'Octavien-Auguste, Coll. de l'École française de Rome 484, Rome, École française de Rome.

LEFÈVRE E. 1976, Der Thyestes des Lucius Varius Rufus. Zehn Überlegungen zu seiner Rekonstruktion, Wiesbaden, Steiner.

- 1993, Horaz: Dichter im augusteischen Rom, Munich, Beck.

LOWRIE M. 1997, Horace's Narrative Odes, Oxford, Clarendon Press.

- 2009, Writing, Performance and Authority in Augustan Rome, Oxford, Oxford University Press.

LYNE R. O. A. M. 1995, Horace. Behind the Public Poetry, New Haven, Yale University Press.

MORELLO R., MORRISON A. D. (ed.) 2007, Ancient Letters. Classical and Late Antique Epistolography, Oxford, Oxford University Press.

NISBET R. G. M., HUBBARD M. 1970, A Commentary on Horace's Odes. Book I, Oxford, Clarendon Press. PASQUALI G. 1920, Orazio lirico, Florence, Le Monnier.

PUTNAM M. C. J. 1995, « Design and Allusion in Odes 1.6 », in S. J. HARRISON (ed.), Homage to Horace. A Bimillenary Celebration, Oxford, Clarendon Press.

REINSBERG C. 1993, Ehe, Hetärentum und Knabenliebe im antiken Griechenland, 2. unv. Aufl., Munich, C. H. Beck.

SMITH P. L. 1969, « Poetic Tensions in the Horatian recusatio », AJPh 89, 1, p. 56-65.

SORDI M. 1993, « Orazio e i temi della propaganda augustea », ACD 29, p. 175-180.

SYNDIKUS H. P. 1972, Die Lyrik des Horaz. Eine Interpretation der Oden, I, Impulse der Forschung 6, Darmstadt, Wissenschaftliche Buchgesellschaft.

VoISIN D. 2001, « Le poète et l'Histoire », VL 163, p. 37-47.

- 2002, « Horace, Agrippa et les recusationes », Latomus 61, 2, p. 352-361.

WALSH T. R. 2005, Fighting Words and Feuding Words. Anger and the Homeric Poems, Greek Studies, Lanham, Lexington Books.

WEST D. 1967, Reading Horace, Edinburgh, Edinburgh University Press.

WIMMEL W. 1960, Kallimachos in Rom. Die Nachfolge seines apologetischen Dichtens in der Augusteerzeit, Hermes. Einzelschriften Heft 16, Wiesbaden, Steiner.

\section{NOTES}

1. [Nec] conamur, tenues grandia (v.9). Les traductions de tenues et de grandia sont évidemment délicates. Je choisis ici de garder la traduction de F. Villeneuve pour la CUF (2002 [1929], p.14), et reviendrai plus loin sur la portée de ces termes et leurs traductions.

2. J'emprunte cette formule à LE DOZE 2014, p. 51.

3. FRAENKEL 1957, p. 233. 
4. C'est un argument que l'on peut mettre en rapport avec les v. 38-41 de l'Art poétique d'Horace.

5. Virgile a recours au même argument dans la bucolique 6 , où il repousse la tentation du genre noble en alléguant les objections d'Apollon (v. 1-9).

6. Catulle, 68 ; Virgile, Ecl. 6 ; Horace, S. 2, 1. Voir aussi à ce sujet WIMMEL 1960.

7. Voir par ex. WICKHAM 1874, p. 32 ; SHOREY 1898 ; KIESSLING, HEINZE 1917, p. 60-61 ; NISBET, HUBBARD 1970, p. 80-90 ; SYNDIKUS 1972, p. 86-94 ; PUTNAM 1995.

8. Je cite ici les premiers mots de AHERN 1991, p. 301, qui emprunte cette expression à NISBET, HUBBARD 1970, p. 83.

9. AHERN 1991, p. 301-302: «My thesis is that Horace has deliberately misrepresented, for humorous effect, the language and action of Homeric poetry. Distortion of Homer serves in the first place to demonstrate, with characteristic slyness [...] Horace's selfproclaimed unfitness to write in praise of Agrippa. But its further and deeper aim is to parody efforts of latter-day Homerizing poets and to illustrate, in the amusing picture that results, Horace's own Alexandrian sensibility. "

10. Pour cette notion de motto, voir PASQUALI 1920 et CAVARZERE 1996.

11. Sauf mentions contraires, les traductions sont personnelles.

12. Sur Agrippa dédicataire de l'ode, voir voisin 2002.

13. Voir par ex. Hymnes homériques 6 (à Aphrodite), v. $2 ; 10$ (à Aphrodite), v. $1 ; 15$ (à Héraclès), v. 1 ; 23 (à Zeus), v. 1.

14. Voir CALAME 1994, p. 397.

15. Voir VoISIN 2001, p. 41.

16. Voir CaIRNS 1995, p. 211-217.

17. Plus élogieuse tout du moins que l'étymologie traditionnelle du praenomen Agrippa : celui qui naît les pieds en premier (voir Pline l'Ancien, Nat. 7, 8).

18. NISBET, HUBBARD 1970, p. 85.

19. KIESSLING, HEINZE 1917, p. 59.

20. Voir DANGEL 2001 et GÀNTAR 1986.

21. TLL, VI, 1, p. 566, 1. 57 sq.

22. Horace, Odes et Épodes, éd. et trad. F. viLLENEUVE, CUF, 2002, p. 14.

23. Horace, Odes and Epodes, ed. and transl. N. RUDD, The Loeb Classical Library. Latin Authors 33, 2004, p. 35.

24. Carm. 1, 32, 6; 1, 35, $10 ; 3,3,44 ; 4,9,21$.

25. Carm. 3, 2, 3; 4, 2, 34-36.

26. Carm. 1, 15, 13.

27. Carm. 1, 37, 29. Le terme ferox participe, dans l'ode, de la constitution d'un portrait ambigu de Cléopâtre qui, désignée d'abord comme un «monstre élu du destin » et « ivre des douceurs de la fortune », devient à la fin du texte une héroïne stoïcienne qui accepte avec sérénité son destin et ne tremble pas devant la mort.

28. L'ambiguïté de ferox dans les Odes peut être rapprochée de celle de l'adjectif atrox: comment comprendre et traduire l'expression praeter atrocem animum Catonis $(2,1,24)$ ?

29. Voir en particulier Carm. 1, 2, 29; 1, 3, 39. 
30. Horace n'en éprouvait certainement aucune honte à l'avènement du principat d'Auguste. La célèbre ode 2, 7 en constitue une preuve évidente. Voir aussi à ce sujet CITRONIL 2000 et la réponse de CALBOLI 2004.

31. voIsin 2001, p. 43.

32. Ces vers sont évidemment à rapprocher des vers $491-492$ de la première géorgique de Virgile qui évoquent la bataille de Philippes : nec fuit indignum superis bis sanguine nostro / Emathiam et latos Haemi pinguiescere campos.

33. Sur ce topos, voir DAVIS 1987.

34. À ce sujet, voir LEFÈVRE 1976.

35. À ce sujet, voir LEFÈVRE 1993, p. 150.

36. Voir WICKHAM 1896, p. 32 ; KIESSLING, HEINZE 1917, p. 60 ; NISBET, HUBBARD 1970, p. 85 ; PUTNAM 1995, p. 53.

37. AHERN 1991, p. 303.

38. Sur ce point, voir en particulier LOWRIE 2009, p. 58-68.

39. KIESSLING, HEINZE 1917, p. 60.

40. R. G. M. Nisbet et M. Hubbard (1970, p. 85) notent « the word is prosaic » et ajoutent la référence à Charisius, Gramm. 1, 271 (=357 Barwick) : tapinosis est rei magnae humilis expositio ut apud Horatium Flaccum Pelidae stomachum cedere nescii.

41. Voir COMMAGER 1962 ; PUTNAM 1995 ; AHERN 1991.

42. Voir AHERN 1991 ; COMMAGER 1962, p. 71, n. 25 ; NISBET, HUBBARD 1970, p. 85 ; PUTNAM 1995 ; SHOREY 1898 ; WEST 1995, p. 29.

43. Voir par ex. pour les Lettres à Atticus : 5,$1 ; 6,3 ; 16,2$ et 16, 3 .

44. Voir à ce sujet le commentaire de A. Kiessling et R. Heinze (1917, p.60): "Stomachus mit den Ableitungen stomachor und stomachosus hat Cicero in der Bedeutung 'Änger' aus der Umgangssprache aufgenommen und, nicht nur in den Briefen ». Voir aussi dans le récent CORBEILL 2015 le chapitre "Cicero's Stomach », et HOFFER 2007.

45. Pour un commentaire précis du passage, voir BRINK 1971, p. 200-201.

46. Stomacho graecus sermo est $(9,696)$.

47. Sur la partie de l'anatomie que désigne stomachus chez Virgile (gorge, poitrine, abdomen ou estomac), voir en particulier HARDIE 1994, p. 219.

48. Lorsque Servius commente les v. 527-528, il renvoie au v. 6 de l'ode 1, 6 d'Horace.

49. S. Commager (1962, p.71) note au sujet de cette expression: "By describing Achilles as 'ignorant of how to yeld', Horace in effect destroys the moral structure of

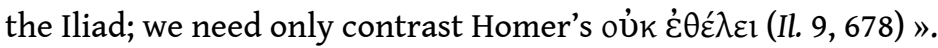

50. S. $2,2,18,38$ et $43 ; 2,3,154 ; 2,4,60 ; 2,8,9$.

51. S. 2, 7, 43-44: [...] aufer / me voltu terrere; manum stomachumque teneto.

52. Voir à ce propos KovACs 2006.

53. $T L L, \mathrm{~V}, 1, \mathrm{p} .2258$ et suiv.

54. Virgile qualifie quant à lui la figure d'Ulysse dans l'Énéide par les adjectifs suivants : pellax $(2,90)$, inventor $(2,164)$ et fandi fictor $(9,602)$.

55. S. 2, 2, 121-122: [...] tum pensilis uva secundas / et nux ornabat mensas cum duplice ficu. 
56. S. 2, 4, 63-64 : est operae pretium duplicis pernoscere iuris / naturam [...].

57. Le TLL donne : Plaute, As. 695 ; Truc. 781.

58. Catulle, 68, 52 : nam mihi quam dederit duplex Amathusia curam / scitis.

59. En relevant cet emprunt du terme à la poésie érotique de Catulle, PUTNAM 1995 , p. 54, suggère que duplex révèle la duplicité amoureuse du héros épique.

60. Homère, Il. 3, $126 ; 10,134 ; 20,415 ; 22,441 ;$ Od. 19, $226 ; 19$, 241. Théocrite, Idylles 25,224 . Voir aussi $\delta i ́ \pi \lambda \alpha \xi$ pour désigner un manteau double chez Apollonios de Rhodes, Argonautiques 1, 326 et 722 .

61. Homère, Il. 4, $133 ; 20,415$.

62. Homère, Il. 23, 243 et 253.

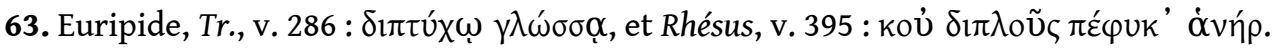

64. Voir NISBET, HUBBARD 1970, p. 85.

65. WEST 1995, p. 29 : «the butt of his humour is himself».

66. AHERN 1991, p. 304.

67. Homère, Il. 1, 81, 192, 226, 245, 387. L'image physiologique des flux de la bile servant chez Homère à évoquer la colère a par ailleurs donné lieu à de nombreuses études. Voir en particulier WALSH 2005.

68. Ars 396-398. À ce sujet, voir l'analyse de BRINK 1971, p. 389, et celle de GALINSKY 1996, p. 226.

69. Voir à ce sujet les nombreuses références données par BRINK 1971, p. 200.

70. Voir COMMAGER 1962, p. 72.

71. Voir NISBET, HUBBARD 1970, p. 88, qui citent Anacréon, 26, et notent que le procédé sera repris plus tard par Ovide (Am. 2, 18).

72. Ovide, Am. 1, 9, 1.

73. Voir REINSBERG 1993, où l'on trouve des références aux jeux érotiques de ces banquets athéniens.

74. Voir le topos de la «muse fluette » dans le prologue des Aitia, frg. 1, 24.

75. Voir à ce sujet HARDIE 2002, et en particulier «Introduction: A Duplicitous Poet ", p. 1-3.

76. Pour l'ensemble du passage de l'Art poétique, voir BRINK 1971, p. 104.

\section{NOTES DE FIN}

*. Je tiens à remercier tout particulièrement Olivier Thévenaz pour ses relectures et ses conseils qui ont grandement contribué à améliorer cet article ainsi que les relecteurs anonymes pour leurs précieuses remarques. 


\section{RÉSUMÉS}

L'ode 1, 6 est une recusatio bien connue et les distorsions de la langue homérique que l'on rencontre dans le poème ont depuis longtemps été bien identifiées par la critique. Cependant, il semble que les commentaires n'ont pas complètement expliqué ce qu'ils nomment communément le ton parodique ou ironique. Par l'étude d'aspects insuffisamment analysés jusqu'alors, cet article a pour but de souligner comment Horace joue avec la langue épique, non pas pour se livrer à un jeu plaisant de subversion de la grandeur homérique ou pour moquer les poètes récents, mais bien pour montrer sa capacité à traiter de la matière et des conventions épiques et faire naître un questionnement sur sa propre poétique.

Horace' Ode I, 6 is a well known recusatio and the distortions of the Homeric language present in the poem have long been recognized by critics. Nevertheless, it seems that commentaries have not thoroughly explained what they commonly name the parodic or ironic tone. Through the study of aspects insufficiently analysed, this article aims at underlying how Horace plays with epic language, not in order to be pleasant in subverting Homeric solemnity or to mock the latter-day poets, but to show his ability to handle epic matter or conventions and raise questions about his own poetry.

\section{INDEX}

nomsmotscles Alcée, Anacréon, Apollonios de Rhodes, Callimaque, Catulle, Cicéron, Euripide, Homère, Horace, Ovide, Pindare, Plaute, Pollion, Théocrite, Varius Rufus, Virgile

Index géographique : Rome

oeuvrecitee Hymnes homériques

Mots-clés : élégie, épopée, genres littéraires, intertextualité, lyrique, parodie, recusatio

Keywords : elegy, epic, literary genres, intertext, lyric, parody, recusatio

\section{AUTEURS}

\section{MARYSE SCHILLING}

Université de Strasbourg, EA 3094 CARRA 